\title{
Management of Maxillary Anterior Supernumerary Teeth
}

\author{
Neena IE ${ }^{1}$, Mebin George Mathew ${ }^{2}$, \\ Poornima $\mathrm{P}^{3}$, Mallikarjun $\mathrm{K}^{4}$, Roopa $\mathrm{KB}^{5}$
}

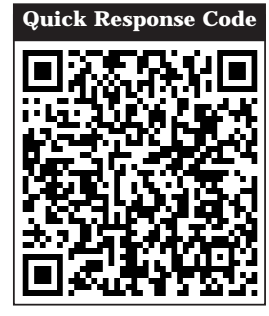

doi: $10.5866 / 2016.8 .10164$

${ }^{1 \& 5}$ Reader

2Post graduate student

${ }^{3}$ Professor and Head of the Department

4Professor,

Department of Pedodontics and Preventive Dentistry,

College Of Dental Sciences,

Davangere -577004, Karnataka, India

\section{Article Info:}

Received: J uly 8, 2016

Review Completed: August 9, 2016

Accepted: September 7, 2016

Available Online: December, 2016 (www.nacd.in)

(c) NAD, 2016 - All rights reserved

\section{Email for correspondence:}

neena.ganesh@gmail.com

\begin{abstract}
:
Supernumerary teeth are the main cause of impaction of upper incisor. Supernumerary teeth when present can cause both esthetic and pathologic problems. Supernumerary teeth in the maxillary midl ineare common. The present case report discusses such type and its management.
\end{abstract}

Key words: Anterior, Maxilla, Supernuemarary.

\section{INTRODUCTION}

Development of the tooth is a continuous process with a number of physiologic growth processes and various morphologic stages interplay to achieve the tooth's final form and structure. An interference in the stage of initiation or any momentary event may result in single or multiple missing teeth or supernumerary teeth. ${ }^{1}$ Supernumerary teeth may be defined as any teeth or tooth substance in excess of the usual configuration of twenty deciduous and thirty-two permanent teeth. ${ }^{2}$ These teeth were first described in 23 and 79 AD. ${ }^{3}$

\section{Case Report}

A 12 year old girl reported to the Department of Pedodontics and Preventive Dentistry with a chi ef complaint of extra teeth in the maxilla. A thorough general examination was done to rule out any syndromes. Medical and family histories were non contributory. The patient had labially proclined maxillary central incisors with incompetent lips (Figure 1). Intraoral examination revealed permanent dentition with two tuberculate supernumerary teeth palatal to the permanent maxillary central incisors (Figure 2). An occlusal radiograph was taken to rule out any other 
unerupted supernumerary teeth (Figure 3). The two supernumerary teeth were extracted (Figure 4) and the patient was referred to the department of orthodontics for orthodontic rehabilitation.

\section{Discussion}

Supernumerary teeth have been reported both in deciduous and permanent dentition with a male predilection. Supernumerary teeth may occur in any area of the dental arch, may be single or multiple, present unilaterally or bilaterally, malformed morphologically or normal in size and shape, straight or inverted in position and may be erupted or impacted. Cases involving one or two supernumerary teeth show a predilection for the anterior maxilla, followed by the mandibular premolar region. In other regions, differences have been reported in the relative frequency of these teeth. Cases involving multiple supernumeraries (more than five) tend to are most commonly seen the mandibular premolar region. ${ }^{2}$

Supernumerary teeth are more commonly found in the Mongoloid racial group with a reported frequency higher than $3 \%{ }^{4}$ Koch et al stated that the prevalence of supernumerary teeth in the permanent dentition is $13 \%$ and the prevalence in primary dentition according to Primosch is 0.3$0.6 \%{ }^{5,6}$ Rajab and Hamden found the prevalence in the primary dentition as $0.3-0.8 \%$ and in the permanent dentition as $0.1-3.8 \%{ }^{7}$

Both genetic and environmental factors play a role in the etiol ogy of supernumerary teeth. ${ }^{8}$ Several theories have been suggested to explain their occurrences:

1. Atavism Theory: This theory suggests that supernumerary teeth were the result of phylogenetic reversion to extinct primates with three pairs of incisors. This theory has been largely discounted. ${ }^{6}$

2. Dichotomy Theory: This stated that the tooth bud splits into two equal or different-sized parts, resulting in the formation of two teeth of equal size, or one normal and one dysmorphic tooth, respectively. However, this theory has al so been discounted. ${ }^{6}$

3. Dental Iamina hyperactivity theory: This involves localized, independent, conditioned hyperactivity of the dental lamina. ${ }^{7}$ According to this theory a supplemental form would develop from the lingual extension of an accessory tooth bud, whereas a rudimentary form would develop from the proliferation of epithelial remnants of the dental lamina. Most literature supports the dental Iamina hyperactivity theory. ${ }^{6}$

Supernumeraries are classified according to morphology or location. Classification based on Morphology: ${ }^{9}$

1. Conical

2. Tuberculate

3. Supplemental

4. Odontomes

Classification Based on Location: ${ }^{10}$

1. Mesiodens

2. Paramolar

3. Distomolar

4. Preparamolar

Complications with supernumerary teeth include: ${ }^{10}$

1. Prevention or delay of eruption of associated permanent teeth

2. Displacement or rotation of permanent teeth

3. Crowding

4. Incomplete space closure during orthodontic treatment

5. Dilaceration, delayed or abnormal root development of associated permanent teeth

6. Root resorption of adjacent teeth

7. Complications with the supernumerary itself

8. Late-forming supernumerary teeth.

Syndromes associated with Supernumerary teeth:10

Developmental disorders that show an association with multiple supernumerary teeth include:

1. Cleftlip and palate

2. Cleidocranial dysostosis

3. Gardner's syndrome

Less common disorders include Fabry Anderson's syndrome, Ehlers-Danlos syndrome, incontinentia pigmenti and Trico Rhino-Phalangeal syndrome. 


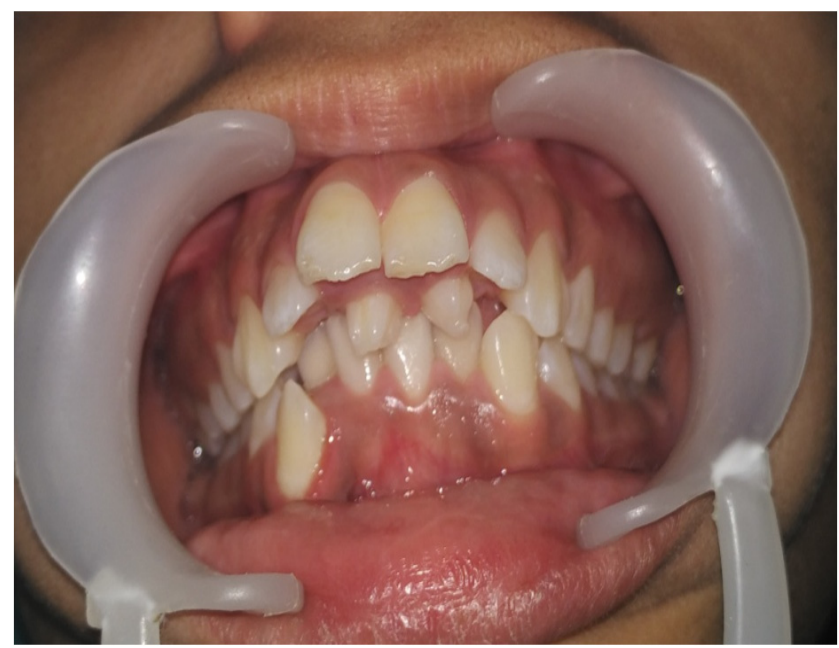

Figure 1: Supernumerary teeth.

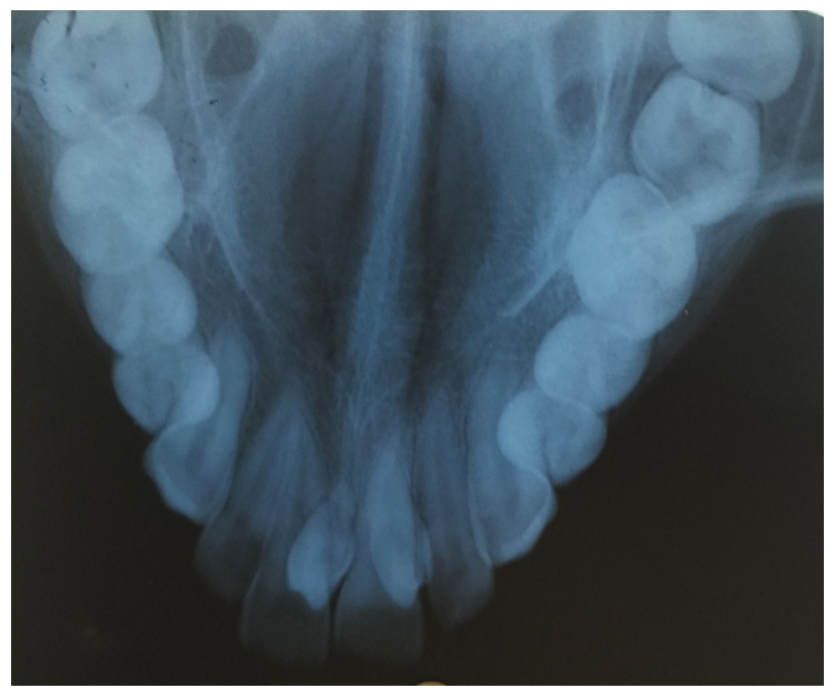

Figure 3: IOPA showing presence of supernumerary teeth.

\section{Treatment}

Treatment of supernumerary teeth includes several controversies and varied opinions among authors, particularly with regard to the timing of removal. Rotberg recommended removal of the supernumerary as soon as it has been discovered and ideally before the age of 5 years so that root formation of the associated permanent incisors is incomplete. ${ }^{11}$ However Koch stated that immediate removal of supernumeraries is not necessary if no pathology is present. ${ }^{5}$ Hogstrum and Andersson suggested two options. The first option involves removal of the supernumerary as soon as it has been

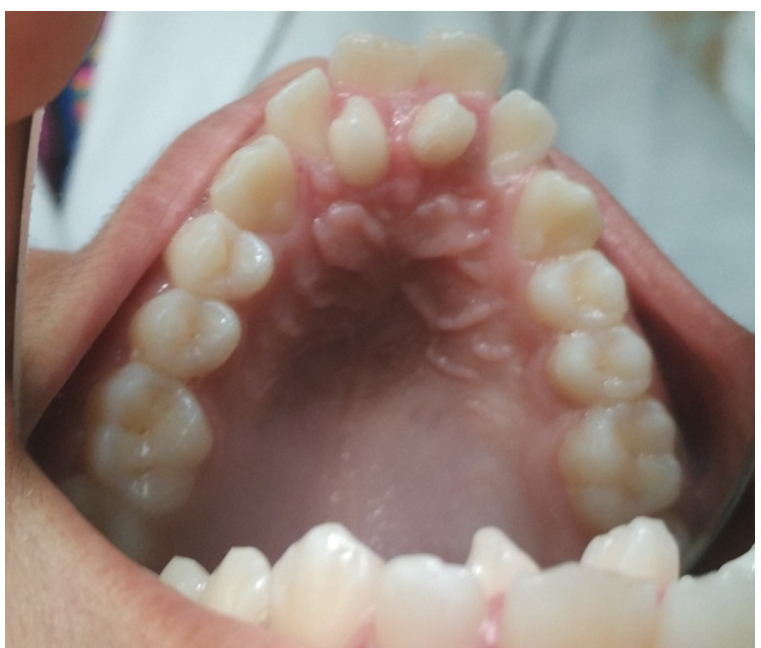

Figure 2: Intraoral examination reveal supernumerary teeth in the maxillary arch.

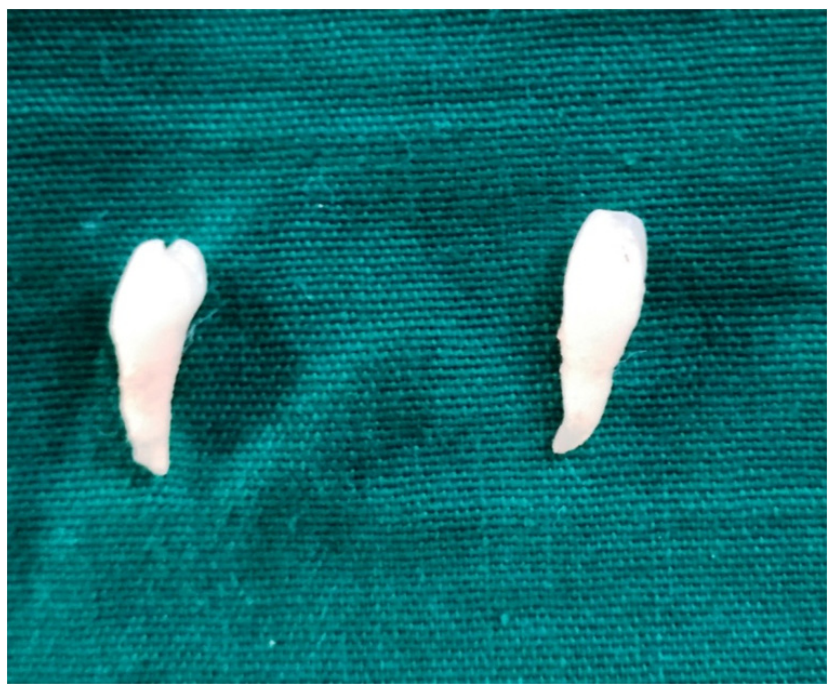

Figure 4: Extracted supernumerary teeth.

diagnosed. This could create dental phobia in a young child and can also cause devitalization or deformation of adjacent teeth. Secondly, the supernumerary could be left until root devel opment of the adjacent teeth is complete. ${ }^{12}$ The potential disadvantages associated with this plan include loss of eruptive force of adjacent teeth, loss of space and crowding of the affected arch, and also possible midline shifts. Shanmugha Devi et al stated that the earlier the offending supernumerary tooth is removed, better will be the prognosis. ${ }^{13}$

According to Garvey et al, extraction is not always the treatment of choice for supernumerary 
teeth. ${ }^{9}$ They may be monitored without removal in cases if satisfactory eruption of related teeth has occurred, if there is no orthodontic treatment required, if there is no associated pathology and if removal would prejudice the vitality of the related teeth. According to Shah et al, if the supernumerary teeth cause no complications and are not likely to interfere with orthodontic tooth treatment, they can be monitored with yearly radiographic review. ${ }^{10}$ The patient should be warned of complications, such as cystic change and migration with damage to nearby roots. If the patient does not wish to risk such complications, it is acceptable to remove the supernumerary teeth. If they are associated with the roots of permanent teeth, it may be apt to wait for the full root development before surgical extraction to minimize the chances of root damage. Omer et al, suggested that if the supernumerary teeth do not cause any discernable adverse effects on adjacent teeth and if no future orthodontic treatment is foreseen, it is reasonable to recommend that immediate surgical intervention is not essential. ${ }^{14}$ Several other authors have also recommended a delayed or conditional removal which appears logical. ${ }^{5}$ Furthermore Koch et al suggested that supernumerary teeth have a tendency to resorb and disappear if left untreated. ${ }^{5}$

\section{References}

1. David Ditto S, Akhila R (2014) Management of Multiple I mpacted Supernumerary Teeth in a Non-Syndromic Patient using Cone Beam CT. Dentistry 4: 190. doi:10.4172/ 2161-1122.1000190.

2. Scheiner MA, Sampson WJ . Supernumerary teeth: A review of the literature and four case reports. Aust Dent J 1997; 42:160-5.
3. Yassin OM, Hamori E. Characteristics, clinical features and treatment of supernumerary teeth. J Clin Pediatr Dent 2009; 33:247-50.

4. Niswander J D, Sujaku C. Congenital anomalies of teeth in the J apanese children. Am J Phys Anthropol 1963; 21:56974.

5. Koch H, Schwartz O, Klausen B. Indications for surgical removal of supernumerary teeth in the premaxilla. Int J Oral Maxillofac Surg1986; 15:273-81.

6. Primosch RE. Anterior supernumerary teeth-assessment and surgical intervention in children. Pediatr Dent 1981; 3:204-15.

7. Rajab LD, Hamdan MA. Supernumerary teeth: Review of the literature and a survey of 152 cases. Int J Paediatr Dent 2002; 12:244-54.

8. Hall A, Onn A. The development of supernumerary teeth in the mandible in cases with a history of supernumeraries in the pre-maxillary region. J Orthod 2006; 33:2505.

9. Garvey MT, Barry HJ , Blake M. Supernumerary teeth - an overview of classification, diagnosis, and management. J Can Dent Assoc 1999; 65:612-6.

10. Shah A, Gill DS, Tredwin C, Naini FB. Diagnosis and management of supernumerary teeth. Dent U pdate 2008; 35(8):510-20.

11. Rotberg S, Kopel HM. Early vs late removal of mesiodens: A clinical study of 375 children. Compend Contin Educ Dent 1984; 5:115-9.

12. Hogstrum A, Andersson L. Complications related to surgical removal of anterior supernumerary teeth in children. ASDC J Dent Child 1987; 54:341-3.

13. Shanmugha Devi G, Arangannal P, Muthu MS, Nirmal L. Supernumerary teeth associated with primary and permanent teeth: A case report. J Indian Soc Pedod Prev Dent 2002; 20:104-6.

14. Omer RS, Anthonappa RP, King NM. Determination of the optimum time for surgical removal of anterior supernumerary teeth. Pediatr Dent 2010; 32:14-20.

\section{Gain quick access to our journal online View our journal at www.nacd.in}

